\title{
An update on anatomy and function of the teleost olfactory system
}

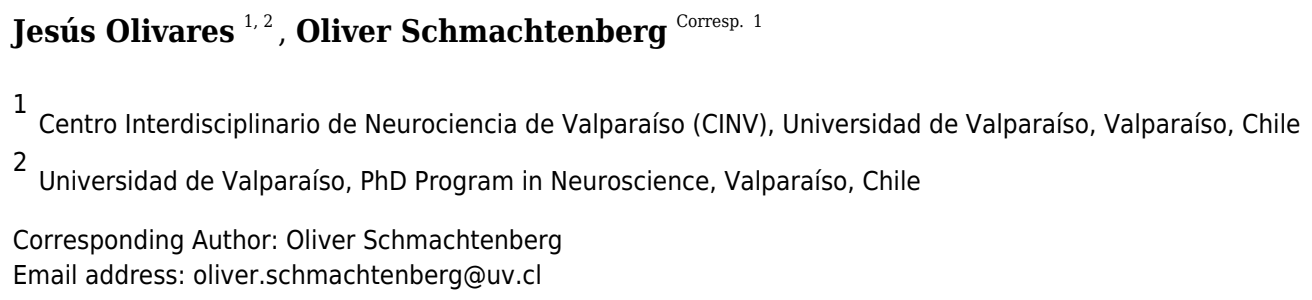

About half of all extant vertebrates are teleost fishes. Although our knowledge about anatomy and function of their olfactory systems still lags behind that of mammals, recent advances in cellular and molecular biology have provided us with a wealth of novel information about the sense of smell in this important animal group. Its paired olfactory organs contain up to five types of olfactory receptor neurons expressing OR, TAAR, VR1and VR2-class odorant receptors associated with individual transduction machineries. The different types of receptor neurons are preferentially tuned towards particular classes of odorants, that are associated with specific behaviors, such as feeding, mating or migration. We discuss the connections of the receptor neurons in the olfactory bulb, the differences in bulbar circuitry compared to mammals, and the characteristics of second order projections to telencephalic olfactory areas, considering the everted ontogeny of the teleost telencephalon. The review concludes with a brief overview of current theories about odor coding and the prominent neural oscillations observed in the teleost olfactory system. 


\section{An update on anatomy and function of the teleost olfactory system}

Jesús Olivares ${ }^{1,2}$, Oliver Schmachtenberg ${ }^{1}$

${ }^{1}$ Centro Interdisciplinario de Neurociencia de Valparaíso (CINV), Universidad de Valparaíso, Valparaíso, Chile

${ }^{2} \mathrm{PhD}$ Program in Neuroscience, Universidad de Valparaíso, Valparaíso, Chile. Current address:

CINV, Universidad de Valparaíso

Corresponding Author:

Oliver Schmachtenberg

Pasaje Harrington 269, Playa Ancha, Valparaíso, 2520000 Chile

Email address: oliver.schmachtenberg@uv.cl 


\section{Abstract}

3 About half of all extant vertebrates are teleost fishes. Although our knowledge about anatomy

4 and function of their olfactory systems still lags behind that of mammals, recent advances in

5 cellular and molecular biology have provided us with a wealth of novel information about the

6 sense of smell in this important animal group. Its paired olfactory organs contain up to five types

7 of olfactory receptor neurons expressing OR, TAAR, VR1- and VR2-class odorant receptors

8 associated with individual transduction machineries. The different types of receptor neurons are

9 preferentially tuned towards particular classes of odorants, that are associated with specific behaviors, such as feeding, mating or migration. We discuss the connections of the receptor neurons in the olfactory bulb, the differences in bulbar circuitry compared to mammals, and the characteristics of second order projections to telencephalic olfactory areas, considering the everted ontogeny of the teleost telencephalon. The review concludes with a brief overview of current theories about odor coding and the prominent neural oscillations observed in the teleost olfactory system.

\section{Introduction}

The sense of smell plays an important role in fishes, mediating behaviors and physiological responses related to food search and feeding, social interaction, mating, detection of predators and contamination, or migration and search for spawning sites (Sorensen \& Caprio, 1998; Bone \& Moore, 2008). As opposed to higher vertebrates (amphibians, reptiles and mammals), which usually have access to a limited degree of light even in moonless nights, fish encounter situations of total darkness easily in turbid or deeper waters and underwater caves, where their olfactory sense may provide a degree of orientation. Olfactory information has long been known to be important for the homing of migrating salmonids and other fishes (Dittman \& Quinn, 1996; Bett \& Hinch, 2016). There is evidence for salmonids that some amino acids dissolved in the water of native rivers could mediate migratory conducts (Yamamoto, Hino \& Ueda, 2010; Yamamoto, Shibata \& Ueda, 2013). However, in general, the identity of the odors mediating orientation behavior in teleosts remains a topic of active investigation. On the other hand, amino acids are considered the most relevant odorants indicating the presence of a food source to teleosts, given 
31 the behavioral responses they generate (Valentinčič, Lamb \& Caprio, 1999; Whitlock, 2006;

32 Calvo-Ochoa \& Byrd-Jacobs, 2019), and the fact that teleosts are generally sensitive to most

amino acids, with electrophysiological screening thresholds ranging from micromolar to nanomolar concentrations $\left(10^{-6}-10^{-8} \mathrm{M}\right)$ (Ivanova \& Caprio, 1993; Nikonov \& Caprio, 2007; Bazáes, Olivares \& Schmachtenberg, 2013; Nikonov et al., 2017; Sato \& Sorensen, 2018).

Nucleic acids and polyamines are also related to food odor, with evidence that several nucleotides, including ATP and adenosine, are able to evoke olfactory responses in channel catfish (Ictalurus punctatus), zebrafish (Danio rerio) and goldfish (Carassius auratus) (Hansen et al., 2003; Rolen et al., 2003; Wakisaka et al., 2017).

Sensitivity thresholds for different types of odorants depend evidently on the species, but also on the type of assay, behavioral versus electrophysiological, and for the latter, whether individual neurons or bulk responses are recorded from the olfactory epithelium, bulb or telencephalon. Studies using electroolfactogram (EOG) recordings have indicated that fish are sensitive to very low concentrations of certain odorants, presenting responses to some amino acids at thresholds in the order of $10^{-9} \mathrm{M}$, and below $10^{-11} \mathrm{M}$ for certain bile salts, steroid hormones and prostaglandins (Reutter \& Kapoor, 2005; Bone \& Moore, 2008). Bile salts are good candidates for social odors, as they are constantly released by fishes (Buchinger, Li \& Johnson, 2014). However, controversy persists as to what degree mixtures of bile salts are species-specific and may therefore be considered pheromonal odors (Sorensen \& Stacey, 2004; Giaquinto \& Hara, 2008). Recently, using EOG recordings in the rainbow trout, responses to lactic acid, pyruvic acid and four $\mathrm{B}$ vitamins with thresholds in the nanomolar range been reported for the first time in rainbow trout, adding these compounds to the growing list of food odors. Lactate and pyruvate are important components of cellular metabolism, while B vitamins, which are synthesized by phytoplankton and algae, are essential for teleost development, which might explain their sensitive detection (Valdés et al., 2015).

Some odorants trigger an instinctive avoidance response. For example, an imminent risk of predation can be detected by fish through the presence of passively released molecules when a conspecific is attacked and injured, which prevail in the environment for much longer than visual or mechanical signals. The skin of teleosts presents a type of cells called club cells that release a combination of chemical warning signals in the context of predation or parasitism, generating changes in the behavior of rainbow trout and other teleost species. These substances include 
62 glycosaminoglycans of chondroitin, an important component of the skin's mucosa (Poulin,

63 Marcogliese \& McLaughlin, 1999; Speedie \& Gerlai, 2008; Wisenden et al., 2009; Mathuru et

64 al., 2012).

65 Here, we provide an update on anatomy and function of the teleost olfactory system, including

66 the important advances achieved during the last years. The review is intended to complement

67 prior major revisions of the relevant literature on fish olfaction, covering peripheral coding and

68 olfactory bulb circuitry (Satou, 1990; Laberge \& Hara, 2001), the olfactory gene repertoire

69 (Korsching, 2009), the variety of olfactory receptor neurons and their respective connections

70 (Hansen et al., 2005; Hamdani \& Døving, 2007; Bazáes, Olivares \& Schmachtenberg, 2013;

71 Yoshihara, 2014) and the generation of olfactory behaviors (Kermen et al., 2013; Yoshihara,

72 2014).

74

75

76

77

\section{Survey methodology}

Initially, a PubMed search was conducted for the terms "teleost" and "olfactory", yielding 304 results. Twenty-two notable and highly cited articles on vertebrate olfaction were also included in the general data base. Four books were additionally considered: "Fish Chemosenses" (Reutter \& Kapoor, 2005); "Biology of Fishes" (Bone \& Moore, 2008); "Comparative Vertebrate Neuroanatomy" (Butler \& Hodos, 2005) and "Sensory Systems Neuroscience" (Hara \& Zielinski, 2007). A total of 116 references was finally selected and included in the review. It should be noted that while the field of teleost olfaction is small compared to other biomedical areas, it is still too large to be comprehensively covered in one review, and no attempt was made in that direction. Particularly, an inter-species comparison was beyond the focus of this work, since the large number of teleosts and their huge variety would render any such attempt hopeless. Instead, we focused on the most popular model species: Channel catfish, rainbow trout, goldfish and zebrafish.

\section{Olfactory epithelium and nerve}

The nasal cavities of teleost fishes, including salmonids such as rainbow trout (Oncorhynchus mykiss), are located on the dorsal anterior face of the head (Fig. 1A, inset). Each cavity has two 
91 openings, allowing entry and outflow of water, propelled by the movement of the fish, muscular 92 pumping actions, ciliary beating of supporting cells, and water currents (Doving et al., 1977).

93 Unlike higher vertebrates, there is no connection between the olfactory and the respiratory systems, and respiratory sniffing and its implications for odor detection are absent, although some fishes may use muscular contractions for active olfactory sampling (Doving et al., 1977; Nevitt, 1991). Teleost fishes lack a separate vomeronasal organ, and the sole olfactory epithelium is located on the floor of the nasal cavity, in most species arranged in the form of sheets or lamellae, which radiate from a central ridge or raphe and give rise to an olfactory rosette (Hansen \& Zielinski, 2005) (Fig. 1A). The number and size of the lamellae increase throughout development of the teleost, but remain relatively constant after the specimen reaches maturity. The lamellae are composed of two pseudostratified epithelial layers that wrap a thin sheet of stroma. Sensory and non-sensory cells are irregularly interspersed within the epithelia, as are mucus-producing goblet cells (Bazáes, Olivares \& Schmachtenberg, 2013) (Fig. 1B). The olfactory epithelium consists of three main types of cells: Olfactory receptor neurons (ORNs), supporting or sustentacular cells, and basal cells, which are capable to divide and regenerate the epithelium after injury (Iqbal \& Byrd-Jacobs, 2010) (Fig. 1D). In teleosts, there are four established types of ORNs intermingled in the olfactory epithelium: Ciliated and microvillous receptor neurons, olfactory crypt cells and Kappe cells, the latter discovered in zebrafish (Hansen et al., 2003; Bazáes, Olivares \& Schmachtenberg, 2013; Ahuja et al., 2015). A putative fifth type of ORN, termed "pear-shaped", was also recently described in zebrafish, and shown to function as an adenosine sensor (Wakisaka et al., 2017). Olfactory cilia and microvilli contain the olfactory receptor proteins that are exposed to chemical stimuli in the water. Ciliated and microvillous ORNs are bipolar cells, with an apical cylindrical dendrite that extends to the surface of the lamellae (Fig. 1B, inset) and an axon that projects towards the submucosa forming the fascicles of the olfactory nerve. These cell types are morphologically and molecularly similar to the ciliated and microvillous ORNs of the main olfactory and vomeronasal organs of higher vertebrates (Farbman, 2000; Hansen et al., 2003). Olfactory crypt cells, which are located in more apical regions of the epithelium, have an oval shape with cilia and microvilli enclosed in an apical invagination, and are completely enveloped by one or two supporting cells of glial characteristics (Hansen \& Finger, 2000; Schmachtenberg, 2006; Bazaes \& Schmachtenberg, 2012). The Kappe cells, found in the most apical epithelial positions, have a similar shape as 
122 crypt cells, but are slightly more slender and do not present cilia (Ahuja et al., 2015). Finally,

123 little is known about the recently described pear-shaped zebrafish ORN, which is

124

125

126

127

128

129

130

131

132

133

134

135

136

137

138

139

140

141

142

143

144

145

146

147

148

149

150

151 morphologically similar to crypt and Kappe cells, but displays different molecular signatures, such as expression of olfactory marker protein (OMP) (Wakisaka et al., 2017). These latter two cell types have hitherto not been described in teleosts other than zebrafish. If they do indeed qualify to be recognized as separate ORN types remains to be confirmed.

\section{Olfactory bulb and tract}

The axonal projections of vertebrate ORNs traverse the skull in olfactory nerve fascicles that enter the olfactory bulbs and converge in spherical neuropil complexes termed glomeruli (Mombaerts et al., 1996). The teleost olfactory bulb has several similarities and some differences with respect to the olfactory bulb of other vertebrates (Satou, 1990; Kermen et al., 2013; Nagayama, Homma \& Imamura, 2014; Calvo-Ochoa \& Byrd-Jacobs, 2019) (Fig. 1C). Recently, an entire olfactory bulb of zebrafish larvae has been reconstructed from serial section electron microscopy, including the skeletons of over 1000 neurons, $75 \%$ of which were identified as mitral cells (Wanner et al., 2016; Wanner, Genoud \& Friedrich, 2016). In the teleost olfactory bulb, four layers can be identified from the periphery towards the center: Olfactory nerve layer, glomerular layer, mitral cell layer and granular layer (Satou, 1990). The outermost layer of this structure corresponds to the layer formed by the axonal endings of the ORNs, which are distributed profusely over the surface of the bulb before traversing deeper into the glomeruli of the glomerular layer, where they form glutamatergic synapses with the dendrites of the mitral cells, whose cell bodies are located in the subjacent layer (Fujita, Satou \& Ueda, 1988). The glomerular layer of teleosts also contains nerve endings from higher telencephalic centers and projections of granule cells, GABAergic cells whose cell bodies are located in the layer that bears the same name and with which the mitral cells share dendrodendritic synapses (Satou, 1990). As opposed to mammals, mitral cells can innervate multiple glomeruli in teleost fish, but not all of them do (Laberge \& Hara, 2001; Fuller, Yettaw \& Byrd, 2006). Bulbar glomeruli are surrounded by short axon cells and periglomerular cells, which participate in this first stage of olfactory processing, together with neuromodulatory efferent projections from the telencephalon making synapses with granular cells in the granular layer of the bulb (Nieuwenhuys, Donkelaar 
152 \& Nicholson, 1998) (Fig. 1F).

153 The tufted cells of mammals are either absent or indistinguishable from mitral cells in the teleost 154 olfactory bulb (Edwards \& Michel, 2002). However, a second type of projection neuron termed 155 ruffed cells has been observed in fish that is not present in mammals (Kosaka \& Hama, 1979, 156 1981). The ruffed cells, which project to the telencephalon together with the mitral cells, also 157 present dendrites in the glomerular layer but only appear to make synapses with granule cells 158 (Kosaka \& Hama, 1979; Satou, 1990). These cells are thought to play an important role in 159 olfactory processing and in the generation of prominent olfactory oscillations in the teleost bulb, 160 since their response is of opposite polarity compared to that of mitral cells (Zippel, 1998) (Fig.

161 1E). The axons of the mitral cells give rise to the olfactory tracts that carry the information to 162 other relay centers in the telencephalon (Nieuwenhuys, Donkelaar \& Nicholson, 1998) (Fig. 1F).

163 Studies using tracers, electrophysiology, genetics and behavior in rainbow trout (Oncorhynchus 164 mykiss), zebrafish (Danio rerio), goldfish (Carassius auratus), crucian carp (Carassius 165 carassius) and other teleosts have allowed to determine the presence of two subdivisions of the 166 olfactory tract: the lateral olfactory tract and the medial olfactory tract (Folgueira, Anadón \& 167 Yáñez, 2004a; Hamdani \& Døving, 2007; Miyasaka et al., 2009, 2014). These can be further 168 subdivided into fiber bundles which conserve the chemotopic organization of the olfactory bulb 169 to some degree, thus maintaining the odotopically organized processing of different types of 170 odors (Finger, 1975; Satou, 1990). In crucian carp, ablation studies of the different olfactory 171 tracts that project to various telencephalic regions indicated that the medial bundle of the median 172 olfactory tract mediates escape behavior in response to odors considered as alarm signals 173 (Hamdani et al., 2000), while the lateral bundle of the median olfactory tract relays odor 174 information related to reproductive behavior (Weltzien et al., 2003). Finally, the lateral olfactory 175 tract has been reported to convey information about odorants related to feeding behaviors in this 176 species (Hamdani, Alexander \& Døving, 2001).

\section{The odor transduction process}

179 In the ciliary and microvillous membranes of vertebrate ORNs, odorant receptor proteins 180 belonging to the OR superfamily of G protein-coupled receptors are expressed (Buck \& Axel, 181 1991). In addition, a subset of receptor neurons express another class of odorant receptor 
182 proteins, termed trace-amine associated receptors (TAARs) (Liberles \& Buck, 2006). A third 183 class of receptor proteins, the vomeronasal receptors (VRs), is expressed within the vomeronasal 184 organ of many higher vertebrates, and in the olfactory epithelium of fishes, where it may serve to 185 detect conspecific odors and pheromones (Silva \& Antunes, 2016). It was demonstrated in 186 several teleost species that the different types of olfactory receptor proteins are expressed 187 differentially in the specific ORN types, which in turn present different transduction processes 188 associated with diverse types of G-proteins (Hansen et al., 2003; Hansen, Anderson \& Finger, 189 2004). While ciliated ORNs generally express receptor proteins of the OR and TAAR types, 190 which are associated with $\mathrm{G} \alpha_{\text {olf }}$ proteins, microvillous receptor neurons present V1R-type receptors associated with $\mathrm{G} \alpha_{\mathrm{i}}$, and V2R receptors coupled to the G-proteins $\mathrm{G} \alpha_{\mathrm{o}}$ (Fig. 1D), G $\alpha_{\mathrm{q}}$, $192 \mathrm{G} \alpha_{\mathrm{q} / 11}$ and $\mathrm{G} \alpha_{\mathrm{i}-3}$. Crypt cells express V1R type receptors coupled to $\mathrm{G} \alpha_{0}, \mathrm{G} \alpha_{\mathrm{q} / 11}$ and $\mathrm{G} \alpha_{\mathrm{i} 1 \mathrm{~b}}$, while 193 Kappe cells, although their class of odorant receptor proteins remains unknown, are thought to be associated with $\mathrm{G} \alpha_{\mathrm{o}}$ proteins (Hansen et al., 2003; Hansen, Anderson \& Finger, 2004; Hansen \& Zielinski, 2005; Bazáes, Olivares \& Schmachtenberg, 2013; Ahuja et al., 2015). The olfactory receptor gene repertoire has been analyzed in several teleost species, revealing a significant degree of variation and diversity, with 189 functional genes and 31 pseudogenes detected in zebrafish, the highest number in teleosts counted to date (Korsching, 2009; Yoshihara, 2014). In the case of salmonid fishes, a total of 60 functional genes and 51 pseudogenes have been found in Salmo salar, which are distributed among the different families of olfactory receptors in such a way that 24 functional OR-type receptors have been found together with 24 pseudogenes, 7 genes of functional V1R-type receptors and 1 pseudogene, and 29 genes of V2R-ype receptors with 26 pseudogenes (Johnstone et al., 2012). More recently, the discovery of 27 putative functional genes and 25 putative pseudogenes of the TAAR family has been added to this list (Tessarolo et al., 2014). The conformational change that the receptor undergoes due to the binding of an odorant induces the activation of the respective $G$ proteins, which dissociate their alpha subunit. In ciliated ORNs of teleosts, as in those of higher vertebrates (Buck \& Axel, 1991), the alpha subunit of the $\mathrm{Ga}_{\text {olf }}$ protein triggers the activation of the enzyme adenylate cyclase, generating an increase in cyclic AMP (cAMP) that functions as a second messenger (Hansen et al., 2003; Schmachtenberg \& Bacigalupo, 2004). cAMP causes the activation of cationic cyclic nucleotide-gated channels 
213 cell membrane directly and by an amplifying effect, through the activation of nearby calcium-

214 dependent chloride channels (Kurahashi \& Yau, 1994; Reisert \& Reingruber, 2019). In addition,

215 calcium contributes to the termination of the response through an adaptive reduction of the

216 sensitivity of CNGCs to cyclic nucleotides by means of calcium-calmodulin activation, until

217 intracellular calcium levels return to pre-stimulation levels mainly by action of the sodium-

218 calcium exchanger (Matthews \& Reisert, 2003). In O. mykiss, the function of calcium-activated

219 chloride channels (termed either Anoctamin 2 or TMEM16B) has been demonstrated directly

220 with patch clamp recordings of ORNs and by electroolfactogram (EOG) recordings of the

221 olfactory organs, indicating that the olfactory transduction process operates in the same way in

222 freshwater fish as in higher vertebrates (Sato \& Suzuki, 2000). In seawater, the large

223 extracellular sodium chloride concentration would make the amplificatory outward chloride

224 currents both unnecessary and impossible (Osorio \& Schmachtenberg, 2013), however, the

225 absence of Anoctamin 2 or TMEM16B channels from ORNs of marine teleosts remains to be

226 shown. The transduction pathways of the other teleost ORN classes are less well understood, and

227 have been reviewed elsewhere (Bazáes, Olivares \& Schmachtenberg, 2013).

228

229 The teleost telencephalon

230 In the brain, sensory input is analyzed and compared with available memories, integrated

231 between different sensory modalities; new memories are formed and behavioral responses may

232 be initiated. Between the main groups of vertebrates, there is a marked difference in the

233 development of the brain, which makes comparative neuroanatomical studies between species

234 difficult. While in vertebrates including lampreys, cartilaginous fish, amphibians and amniotes,

235 the telencephalon develops from the neural tube through a process called evagination, in teleost

236 fishes a process called eversion is generated, in which structures of the brain are distributed

237 differently (Butler, 2000; Butler \& Hodos, 2005; Folgueira et al., 2012). Evagination is produced

238 by the expansion of the lumen of the neural tube, which gives rise to the lateral ventricles inside

239 the telencephalon. The eversion process, however, generates a telencephalon without cavities,

240 developing a ventricular surface located dorsally (Nieuwenhuys, 2011). Although the sections of

241 the neural tube that give rise to the different functional cortical regions of species generating the

242 evagination process are homologous to those found in teleost fishes, once the eversion process is 
243 completed during embryonic development, the functional regions, including those that process

244 olfactory information, present a disposition that differs greatly from the other groups of vertebrates (Butler \& Hodos, 2005; Ito \& Yamamoto, 2009; Folgueira et al., 2012). A distinctive

246 feature of the mammalian telencephalon is the presence of a neocortex or six-layer pallium,

247 which is considered responsible for superior cognitive functions. The pallium of the teleost fishes

248 lacks a six-layer cortex, and even laminar structures. Instead, the teleost telencephalon contains zones and nuclei that are neuroanatomically and functionally analogous to the pallial and subpallial structures of evaginating vertebrates (Ito \& Yamamoto, 2009). In the teleost telencephalon, two regions defined by topographic criteria can be recognized: The dorsal area (Area Dorsalis Telencephali), and the ventral area (Area Ventralis Telencephali) considered homologous to the pallium and the subpallium, respectively, of the remainder of vertebrates. Both telencephalic regions were shown to receive bulbar projections in zebrafish (Miyasaka et al., 2014). These telencephalic areas have been subdivided into zones and nuclei by various authors, among which the ventral area of the telencephalon can be distinguished into a central (Vc), ventral (Vv), dorsal (Vd), lateral (Vl); supracomissural (Vs) and paracomissural (Vp) nucleus, while the dorsal area can be subdivided into a central (Dc), dorsal (Dd), lateral (D1), medial (Dm) and posterior (Dp) zone (Nieuwenhuys, Donkelaar \& Nicholson, 1998; Wullimann \& Rink, 2002; Folgueira, Anadón \& Yáñez, 2004b; Biechl et al., 2017) (Fig. 1F). It should be noted however, that in rainbow trout, the dorsal and the dorsolateral region of the dorsal area of the telencephalon (Dd + Dl-d), have been proposed to form a homogeneous region according to cytoarchitectonic and neurochemical criteria (Folgueira, Anadón \& Yáñez, 2004b). The differences in the development of the teleost telencephalon make it difficult to identify areas that are functionally homologous to the telencephalon of other vertebrates. Studies analyzing neurochemistry, connectivity, gene expression and development in several species of teleosts suggest that the nuclei located dorsally within the Area Ventralis, Vc and Vd, represent the striatum of other vertebrates. Also, the Vs represents subpallial tonsillar regions, and Vv and V1, located ventrally in the telencephalon, could represent the septum, with Vv being a homologue of the lateral septum, the nucleus accumbens and the substantia innominata, which are related to the reward system. In the dorsal area of the telencephalon, Dc represents the pallium, the most

272 medial part of Dm is thought to be analogous to portions of the amygdala, and Dl is likely homologous to the hippocampus. 
274 Studies in different species of teleosts have established the pallial regions and the subpallial

275 nuclei that receive projections from the olfactory bulb: Dp, D1, Vv, Vs, Vp, Vc, Vl, among which

276 the Vv region stands out related to the reward systems, and Dp related to the identity of odorants.

277 Dp is the main target of the secondary olfactory fibers (Fig. 1F), comparable to the primary

278 olfactory cortex or piriform cortex of higher vertebrates (Wullimann, Rupp \& Reichert, 1996;

279 Nieuwenhuys, Donkelaar \& Nicholson, 1998; Cerdá-Reverter, Zanuy \& Muñoz-Cueto, 2001;

280 Wullimann \& Rink, 2002; Folgueira, Anadón \& Yáñez, 2004a,b; Butler \& Hodos, 2005; Mueller

281 et al., 2011; Kermen et al., 2013; Biechl et al., 2017). Olfactory stimulation causes patterns of

282 activity in specific sectors of the olfactory bulb and in the Vv and Dp sectors of the

283 telencephalon in channel catfish and zebrafish (Nikonov, Finger \& Caprio, 2005; Yaksi et al.,

284 2009). Blumhagen showed that extracellular recordings of the Dp region of zebrafish are

285 synchronized with the activity of mitral cells after olfactory stimulation (Blumhagen et al.,

286 2011). This is in line with evidence supporting the notion that the Vv and Dp regions of the

287 teleost telencephalon are analogous to structures related to olfactory processing and learning in

288 higher vertebrates (Butler \& Hodos, 2005; Ito \& Yamamoto, 2009; Mueller et al., 2011).

289

\section{Olfactory coding in teleosts}

291 The coding of olfactory information regarding stimulus identity, intensity, time course and spatial origin occurs at different levels of the olfactory system, allowing parallel and differentiated processing of different aspects of the olfactory stimuli. Initial coding occurs at the level of the olfactory epithelium and is determined by the types and numbers of ORNs that are activated (Kang \& Caprio, 1995; Duchamp-Viret, Duchamp \& Chaput, 2000). The information is odotopically organized in the olfactory bulb and modified by efferent input and complex circuits formed by local interneurons, as in higher vertebrates (Li et al., 2019). Finally, a percept is thought to be generated at the level of several telencephalic regions (Wilson \& Mainen, 2006). In the olfactory epithelium, ORNs choose and express one allele of the olfactory receptor gene repertoire (Khan, Vaes \& Mombaerts, 2011), and receptor neuron groups of variable size that express a common olfactory receptor gene send their axons to the same pair of glomeruli in the bulb. Since odorant receptor proteins are generally of a broad spectrum and activated by different, albeit mostly structurally similar molecules, each odor activates a practically unique 
304 combination of ORNs in the olfactory epithelium, and of glomeruli in the olfactory bulb (Malnic 305 et al., 1999; Wilson \& Mainen, 2006). The combination of the afferents of many ORNs in the 306 olfactory bulb also causes an increase in signal strength and helps reduce the noise associated 307 with local fluctuations in odorant concentration (Kay \& Stopfer, 2006).

308 In fish, the projections of the diverse types of ORNs reach different sectors of the olfactory bulb, 309 although there is also evidence that a small subpopulation of ORNs projects directly to the 310 ventral region of the telencephalon (Hara \& Zielinski, 2007; Tierney, 2015).

311 Electrophysiological studies in trout and channel catfish have confirmed that different types of 312 odorants are processed in different parts of the olfactory bulb, generating a gross general odotopy 313 (Friedrich \& Korsching, 1997; Hara \& Zhang, 1998; Nikonov \& Caprio, 2004, 2005; Nikonov, 314 Finger \& Caprio, 2005; Rolen \& Caprio, 2007). Using retrograde tracers in channel catfish, it 315 was observed that the ciliated ORNs project their axons to medial regions of the olfactory bulb, 316 which are activated by bile salts, and ventral regions, which respond to amino acids, while the 317 microvillous ORNs project mainly to the dorsal surface of the bulb, where mainly responses to 318 amino acids (anterior region) and nucleotides (posterior region) are observed. These separate 319 innervation patterns of the two main types of teleost ORNs were beautifully confirmed in 320 transgenic zebrafish (Sato, Miyasaka \& Yoshihara, 2005).

321 Furthermore, immunohistochemical studies of zebrafish crypt cells have shown that these project 322 to the single posterior mediodorsal glomerulus 2 (mdG2) in the olfactory bulb (Ahuja et al., 323 2013), which may be involved in pheromone and/or kin recognition (Bazaes \& Schmachtenberg, 324 2012; Biechl et al., 2016). Kappe cells also project to a single glomerulus, posterior mediodorsal 325 glomerulus 5 (mdG5) in zebrafish (Hansen et al., 2003, 2005; Ahuja et al., 2013, 2015; Kress, 326 Biechl \& Wullimann, 2014), but their function(s) remain enigmatic to date. Thus, the general 327 odotopic map of vertebrate olfactory bulbs is complemented by a coarser ORN type and odorant 328 class-dependent map in teleost fishes.

329 Odors usually represent complex mixtures that involve many odorants, and the perception of 330 odors does not generally allow the identification of individual components, unless they are 331 limited in number, as elegantly demonstrated in the catfish Ameiurus melas (Valentincic et al., 332 2011). Instead, the components are united generating a recognition based on patterns (Laurent, 333 2002). The olfactory system is able to decompose odors with different degrees of resolution,

334 from a qualitative point of view, thus recognizing the "family" of odorants with which the 
335 perceived odor is related. Changes in odor concentration can also be determined, which may 336 affect the perceived smell quality (Friedrich \& Laurent, 2001; Laurent, 2002). This process of 337 decoding the depends on the complete olfactory system, involving an analysis at the 338 telencephalic level, which acts as a secondary relay of odor information (Yaksi et al., 2009). The 339 first relay, the bulb, performs the task of de-correlating the information, thus increasing the 340 coding space, implying a decrease in the overlap, over time, between odorant mixtures

341 (Friedrich, Laurent \& Rainer, 2004). In this process, patterns of oscillatory activity are generated 342 in response to odor stimulation, which are the result of the summation of synaptic activity of 343 multiple afferent neurons (Laberge \& Hara, 2001; Friedrich, Habermann \& Laurent, 2004; 344 Buzsáki \& Draguhn, 2004; Schoppa, 2006). In teleost fishes, olfactory stimulation causes 345 patterns of transient oscillatory activity in specific sectors of the olfactory bulb and in the Vv and 346 Dp sectors of the telencephalon in channel catfish, zebrafish and rainbow trout (Nikonov, Finger 347 \& Caprio, 2005; Yaksi et al., 2009; Olivares, 2019) (Fig. 1E). The most prominent oscillations 348 are observed in the $7-12 \mathrm{~Hz}$ range, which may functionally correspond to the beta-range in 349 mammals (Satou \& Ueda, 1978; Satou, 1990; Kay et al., 2009). As early as in 1938, Adrian had 350 been able to observe and record oscillations in the central olfactory system of decapitated fish, 351 using different methods of mechanical and chemical stimulation (Adrian \& Ludwig, 1938). Blumhagen et al. (2011), showed that local field potential recordings of the Dp region of zebrafish are synchronized with the activity of mitral cells recorded during olfactory stimulation (Blumhagen et al., 2011). There is mounting evidence indicating that the origin of oscillations in the olfactory system is the olfactory bulb (Satou \& Ueda, 1978; Kay, 2014). Although the role of oscillations evoked by odors in the olfactory system of vertebrates is not yet understood, one attractive possibility is that the synchronization of neural networks at specific frequencies allows to isolate transient communication pathways between distant brain regions (Buzsáki \& Draguhn, 2004). The different types of oscillations observed in the olfactory system differ in frequency and power depending on the behavioral state of the animal, however, the frequency ranges used

361 for the classification of these signals are species-specific, and generally significantly lower in 362 fishes than in mammals (Kay et al., 2009). 


\section{Conclusions}

365 The teleost olfactory system displays important cellular, anatomical and functional differences

366 compared to other classes of vertebrates. These are in part due to the aqueous nature of their

367 habitat, the presence of a sole type of olfactory organ compared to up to five in mammals, and

368 the separation of the olfactory from the respiratory system in fishes. Ciliated and microvillous

369 ORNs have conserved features across vertebrates, whereas olfactory crypt, pear-shaped and

370 Kappe cells appear unique to fishes. The teleost olfactory bulb lacks tufted cells but contains

371 ruffed cells instead, and mitral cells may innervate more than one glomerulus. Olfactory tracts to

372 the telencephalon preserve the bulbar odotopy among their bundles and innervate telencephalic

373 areas that are functionally but not anatomically homologous to higher vertebrates. Prominent

374 field potential oscillations, of lower frequency than in mammals and lacking respiratory rhythms,

375 are observed in response to odorant stimulation, originating in the olfactory bulb and expanding

376 through the olfactory tracts to olfactory telencephalic areas. Future studies will, among others,

377 define the species-specific odors guiding migratory behavior in certain teleosts, notably in

378 salmonids, clarify how olfactory memories are created and stored, define the roles of pear-

379 shaped and Kappe cells, and hopefully elucidate the function of the olfactory oscillations, which

380 has remained enigmatic for decades. 
382

383

384

385

386

387

388

389

390

391

392

393

394

395

396

397

398

399

400

401

402

403

404

405

406

407

408

409

410

411

412

413

414

415

416

417

418

419

420

421

422

423

424

425

426

\section{References}

Adrian ED, Ludwig C. 1938. Nervous discharges from the olfactory organs of fish. The Journal of physiology 94:441-60.

Ahuja G, Ivandic I, Saltürk M, Oka Y, Nadler W, Korsching SI. 2013. Zebrafish crypt neurons project to a single, identified mediodorsal glomerulus. Scientific reports 3:2063. DOI: $10.1038 /$ srep02063.

Ahuja G, Nia SB, Zapilko V, Shiriagin V, Kowatschew D, Oka Y, Korsching SI. 2015. Kappe neurons, a novel population of olfactory sensory neurons. Scientific Reports 4:1-8. DOI: 10.1038/srep04037.

Bazáes A, Olivares J, Schmachtenberg O. 2013. Properties, Projections, and Tuning of Teleost Olfactory Receptor Neurons. Journal of Chemical Ecology 39:451-464. DOI: 10.1007/s10886-013-0268-1.

Bazaes A, Schmachtenberg O. 2012. Odorant tuning of olfactory crypt cells from juvenile and adult rainbow trout. Journal of Experimental Biology 215:1740-1748. DOI: 10.1242/jeb.067264.

Bett NN, Hinch SG. 2016. Olfactory navigation during spawning migrations: a review and introduction of the Hierarchical Navigation Hypothesis. Biological reviews of the Cambridge Philosophical Society 91:728-759. DOI: 10.1111/brv.12191.

Biechl D, Tietje K, Gerlach G, Wullimann MF. 2016. Crypt cells are involved in kin recognition in larval zebrafish. Scientific Reports 6:24590. DOI: 10.1038/srep24590.

Biechl D, Tietje K, Ryu S, Grothe B, Gerlach G, Wullimann MF. 2017. Identification of accessory olfactory system and medial amygdala in the zebrafish. Scientific Reports 7:1-17. DOI: $10.1038 /$ srep44295.

Blumhagen F, Zhu P, Shum J, Schärer Y-PZ, Yaksi E, Deisseroth K, Friedrich RW. 2011. Neuronal filtering of multiplexed odour representations. Nature 479:493-8. DOI: 10.1038 /nature 10633 .

Bone Q, Moore R. 2008. Biology of Fishes. Saunders College Publishing. DOI: 10.1080/17451000902889821.

Buchinger TJ, Li W, Johnson NS. 2014. Bile salts as semiochemicals in fish. Chemical Senses 39:647-654. DOI: 10.1093/chemse/bju039.

Buck L, Axel R. 1991. A novel multigene family may encode odorant receptors: A molecular basis for odor recognition. Cell 65:175-187. DOI: 10.1016/0092-8674(91)90418-X.

Butler AB. 2000. Topography and topology of the teleost telencephalon: A paradox resolved. Neuroscience Letters 293:95-98. DOI: 10.1016/S0304-3940(00)01497-X.

Butler AB, Hodos W. 2005. Comparative vertebrate neuroanatomy: Evolution and Adaptation. John Wiley \& Sons, Inc., Hoboken, New Jersey.

Buzsáki G, Draguhn A. 2004. Neuronal oscillations in cortical networks. Science (New York, N.Y.) 304:1926-9. DOI: 10.1126/science.1099745.

Calvo-Ochoa E, Byrd-Jacobs CA. 2019. The olfactory system of zebrafish as a model for the study of neurotoxicity and injury: Implications for neuroplasticity and disease. International Journal of Molecular Sciences 20. DOI: 10.3390/ijms20071639.

Cerdá-Reverter JM, Zanuy S, Muñoz-Cueto JA. 2001. Cytoarchitectonic study of the brain of a perciform species, the sea bass (Dicentrarchus labrax). I. The telencephalon. Journal of Morphology 247:217-228.

Dittman A, Quinn T. 1996. Homing in Pacific salmon: mechanisms and ecological basis. The 
Journal of Experimental Biology 199:83-91.

Doving KB, Dubois-Dauphin M, Holley A, Jourdan F. 1977. Functional Anatomy of the Olfactory Organ of Fish and the Ciliary Mechanism of Water Transport. Acta Zoologica 58:245-255.

Duchamp-Viret P, Duchamp A, Chaput MA. 2000. Peripheral odor coding in the rat and frog: quality and intensity specification. The Journal of Neuroscience 20:2383-2390. DOI: citeulike-article-id:9521592.

Edwards JG, Michel WC. 2002. Odor-stimulated glutamatergic neurotransmission in the zebrafish olfactory bulb. Journal of Comparative Neurology 454:294-309. DOI: 10.1002/cne.10445.

Farbman AI. 2000. Cell biology of olfactory epithelium. In: Finger TE, Silver WL, Restrepo D eds. The Neurobiology of taste and smell. Wiley, New York, 131-158.

Finger TE. 1975. The distribution of the olfactory tracts in the bullhead catfish, Ictalurus nebulosus. Journal of Comparative Neurology 161:125-141. DOI: 10.1002/cne.901610110.

Folgueira M, Anadón R, Yáñez J. 2004a. An experimental study of the connections of the telencephalon in the rainbow trout (Oncorhynchus mykiss). I: Olfactory bulb and ventral area. Journal of Comparative Neurology 480:180-203. DOI: 10.1002/cne.20340.

Folgueira M, Anadón R, Yáñez J. 2004b. Experimental study of the connections of the telencephalon in the rainbow trout (Oncorhynchus mykiss). II: Dorsal area and preoptic region. Journal of Comparative Neurology 480:204-233. DOI: 10.1002/cne.20341.

Folgueira M, Bayley P, Navratilova P, Becker TS, Wilson SW, Clarke JD. 2012. Morphogenesis underlying the development of the everted teleost telencephalon. Neural Development 7:113.

Friedrich RW, Habermann CJ, Laurent G. 2004. Multiplexing using synchrony in the zebrafish olfactory bulb. Nature Neuroscience 7:862-871. DOI: 10.1038/nn1292.

Friedrich RW, Korsching SI. 1997. Combinatorial and chemotopic odorant coding in the zebrafish olfactory bulb visualized by optical imaging. Neuron 18:737-752. DOI: 10.1016/S0896-6273(00)80314-1.

Friedrich RW, Laurent G. 2001. Dynamic optimization of odor representations by slow temporal patterning of mitral cell activity. Science (New York, N.Y.) 291:889-94. DOI: 10.1126/science.291.5505.889.

Friedrich RW, Laurent G, Rainer W. 2004. Dynamics of olfactory bulb input and output activity during odor stimulation in zebrafish. Journal of neurophysiology 91:2658-69. DOI: 10.1152/jn.01143.2003.

Fujita I, Satou M, Ueda K. 1988. Morphology of physiologically identified mitral cells in the carp olfactory bulb: A light microscopic study after intracellular staining with horseradish peroxidase. Journal of Comparative Neurology 267:253-268. DOI: 10.1002/cne.902670208.

Fuller CL, Yettaw HK, Byrd CA. 2006. Mitral cells in the olfactory bulb of adult zebrafish (Danio rerio): morphology and distribution. Journal of Comparative Neurology 499:218230.

Giaquinto P, Hara TJ. 2008. Discrimination of bile acids by the rainbow trout olfactory system: Evidence as potential pheromone. Biological Research 41:33-42. DOI: 10.4067/S071697602008000100005.

Hamdani EH, Alexander G, Døving KB. 2001. Projection of sensory neurons with microvilli to the lateral olfactory tract indicates their participation in feeding behaviour in crucian carp. 
491

492

493

494

495

496

497

498

499

500

501

502

503

504

505

506

507

508

509

510

511

512

513

514

515

516

517

518

Chemical senses 26:1139-1144.

Hamdani EH, Døving KB. 2007. The functional organization of the fish olfactory system. Progress in Neurobiology 82:80-86. DOI: 10.1016/j.pneurobio.2007.02.007.

Hamdani EH, Stabell OB, Alexander G, Døving KB. 2000. Alarm reaction in the crucian carp is mediated by the medial bundle of the medial olfactory tract. Chemical senses 25:103-9.

Hansen A, Anderson KT, Finger TE. 2004. Differential distribution of olfactory receptor neurons in goldfish: Structural and molecular correlates. Journal of Comparative Neurology 477:347-359. DOI: 10.1002/cne.20202.

Hansen A, Finger TE. 2000. Phyletic distribution of crypt-type olfactory receptor neurons in fishes. Brain, Behavior and Evolution 55:100-110. DOI: 10.1159/000006645.

Hansen A, Rolen SH, Anderson K, Morita Y, Caprio J, Finger TE. 2003. Correlation between olfactory receptor cell type and function in the channel catfish. The Journal of Neuroscience 23:9328-9339. DOI: 23/28/9328 [pii].

Hansen A, Rolen SH, Anderson K, Morita Y, Caprio J, Finger TE. 2005. Olfactory receptor neurons in fish: Structural, molecular and functional correlates. Chemical Senses 30 SUPPL.:2005. DOI: 10.1093/chemse/bjh239.

Hansen A, Zielinski BS. 2005. Diversity in the olfactory epithelium of bony fishes: Development, lamellar arrangement, sensory neuron cell types and transduction components. Journal of Neurocytology 34:183-208. DOI: 10.1007/s11068-005-8353-1.

Hara TJ, Zhang C. 1998. Topographic Bulbar Projections and Dual Neural Pathways of the Primary Olfactory Neurons in Salmonid Fishes. Neuroscience 82:301-313.

Hara TJ, Zielinski B. 2007. Sensory Systems Neuroscience. Academic Press, Elsevier. DOI: 10.1016/S1546-5098(06)25006-4.

Iqbal T, Byrd-Jacobs C. 2010. Rapid degeneration and regeneration of the zebrafish olfactory epithelium after triton x-100 application. Chemical Senses 35:351-361. DOI: 10.1093/chemse/bjq019.

Ito H, Yamamoto N. 2009. Non-laminar cerebral cortex in teleost fishes? Biology letters 5:11721. DOI: $10.1098 / \mathrm{rsbl} .2008 .0397$.

Ivanova TT, Caprio J. 1993. Odorant receptors activated by amino acids in sensory neurons ot the channel catfishIctalurus punctatus. J. Gen. Physiol. 102:1085-1105.

Johnstone KA, Lubieniecki KP, Koop BF, Davidson WS. 2012. Identification of olfactory receptor genes in Atlantic salmon Salmo salar. Journal of Fish Biology 81:559-575. DOI: 10.1111/j.1095-8649.2012.03368.x.

Kang J, Caprio J. 1995. In Vivo Responses of Single Olfactory Receptor Neurons in the Channel Catfish, Ictalurus punctatus. Journal of Neurophysiology 73:172-177.

Kay LM. 2014. Circuit oscillations in odor perception and memory. Progress in Brain Research 208:223-251. DOI: 10.1016/B978-0-444-63350-7.00009-7.

Kay LM, Beshel J, Brea J, Martin C, Rojas-Libano D, Kopell N. 2009. Olfactory oscillations: the what, how and what for. Trends in Neurosciences 32:207-214. DOI: 10.1016/j.tins.2008.11.008.

Kay LM, Stopfer M. 2006. Information processing in the olfactory systems of insects and vertebrates. Seminars in Cell and Developmental Biology 17:433-442. DOI: 10.1016/j.semcdb.2006.04.012.

Kermen F, Franco LM, Wyatt C, Yaksi E. 2013. Neural circuits mediating olfactory-driven behavior in fish. Frontiers in neural circuits 7:62. DOI: 10.3389/fncir.2013.00062.

Khan M, Vaes E, Mombaerts P. 2011. Regulation of the probability of mouse odorant receptor 
gene choice. Cell 147:907-921. DOI: 10.1016/j.cell.2011.09.049.

Korsching S. 2009. The Molecular Evolution of Teleost Olfactory Receptor Gene Families. In: Chemosensory Systems in Mammals, Fishes, and Insects. 221-238. DOI: 10.1007/400.

Kosaka T, Hama K. 1979. Ruffed cell: A new type of neuron with a distinctive initial unmyelinated portion of the axon in the olfactory bulb of the goldfish (Carassius auratus). The Journal of Comparative Neurology 186:301-320. DOI: 10.1002/cne.901930109.

Kosaka T, Hama K. 1981. Ruffed cell: A new type of neuron with a distinctive initial unmyelinated portion of the axon in the olfactory bulb of the goldfish (Carassius auratus). The Journal of Comparative Neurology 201:571-587. DOI: 10.1002/cne.901930109.

Kress S, Biechl D, Wullimann MF. 2014. Combinatorial analysis of calcium-binding proteins in larval and adult zebrafish primary olfactory system identifies differential olfactory bulb glomerular projection fields. Brain Structure and Function 220:1951-1970. DOI: 10.1007/s00429-014-0765-1.

Kurahashi T, Yau KW. 1994. Olfactory Transduction: Tale of an unusual chloride current. Current Biology 4:256-258. DOI: 10.1016/S0960-9822(00)00058-0.

Laberge F, Hara TJ. 2001. Neurobiology of fish olfaction: A review. Brain Research Reviews 36:46-59. DOI: 10.1016/S0165-0173(01)00064-9.

Laurent G. 2002. Olfactory network dynamics and the coding of multidimensional signals. Nature reviews. Neuroscience 3:884-895. DOI: 10.1038/nrn964.

Li A, Rao X, Zhou Y, Restrepo D. 2019. Complex neural representation of odor information in the olfactory bulb. Acta Physiologica:e13333. DOI: 10.1111/apha.13333.

Liberles SD, Buck LB. 2006. A second class of chemosensory receptors in the olfactory epithelium. Nature 442:645-650. DOI: 10.1038/nature05066.

Malnic B, Hirono J, Sato T, Buck LB. 1999. Combinatorial receptor codes for odors. Cell 96:713-23. DOI: 10.1016/S0092-8674(00)80581-4.

Mathuru AS, Kibat C, Cheong WF, Shui G, Wenk MR, Friedrich RW, Jesuthasan S. 2012. Chondroitin fragments are odorants that trigger fear behavior in fish. Current Biology 22:538-544. DOI: 10.1016/j.cub.2012.01.061.

Matthews HR, Reisert J. 2003. Calcium, the two-faced messenger of olfactory transduction and adaptation. Current Opinion in Neurobiology 13:469-475. DOI: 10.1016/S09594388(03)00097-7.

Miyasaka N, Arganda-Carreras I, Wakisaka N, Masuda M, Sümbül U, Seung HS, Yoshihara Y. 2014. Olfactory projectome in the zebrafish forebrain revealed by genetic single-neuron labelling. Nature Communications 5. DOI: 10.1038/ncomms4639.

Miyasaka N, Morimoto K, Tsubokawa T, Higashijima S -i., Okamoto H, Yoshihara Y. 2009. From the Olfactory Bulb to Higher Brain Centers: Genetic Visualization of Secondary Olfactory Pathways in Zebrafish. Journal of Neuroscience 29:4756-4767. DOI: 10.1523/JNEUROSCI.0118-09.2009.

Mombaerts P, Wang F, Dulac C, Chao SK, Nemes A, Mendelsohn M, Edmondson J, Axel R. 1996. Visualizing an olfactory sensory map. Cell 87:675-686. DOI: 10.1016/S00928674(00)81387-2.

Mueller T, Dong Z, Berberoglu MA, Guo S. 2011. The dorsal pallium in zebrafish, Danio rerio (Cyprinidae, Teleostei). Brain research 1381:95-105. DOI: 10.1016/j.brainres.2010.12.089. Nagayama S, Homma R, Imamura F. 2014. Neuronal organization of olfactory bulb circuits. Frontiers in Neural Circuits 8:1-19. DOI: 10.3389/fncir.2014.00098.

Nevitt GA. 1991. Do fish sniff? A new mechanism of olfactory sampling in pleuronectid 
flounders. The Journal of Experimental Biology 157:1-18.

Nieuwenhuys R. 2011. The development and general morphology of the telencephalon of actinopterygian fishes: Synopsis, documentation and commentary. Brain Structure and Function 215:141-157. DOI: 10.1007/s00429-010-0285-6.

Nieuwenhuys R, Donkelaar HJ Ten, Nicholson C. 1998. Chapter 15 Holosteans and Teleosts. In: The Central Nervous System of Vertebrates Volume 2. Springer, 900-913.

Nikonov AA, Butler JM, Field KE, Caprio J, Maruska KP. 2017. Reproductive and metabolic state differences in olfactory responses to amino acids in a mouth brooding African cichlid fish. The Journal of Experimental Biology 220:2980-2992. DOI: 10.1242/jeb.157925.

Nikonov AA, Caprio J. 2004. Odorant Specificity of Single Olfactory Bulb Neurons to Amino Acids in the Channel Catfish. J Neurophysiol 92:386-397.

Nikonov AA, Caprio J. 2005. Processing of odor information in the olfactory bulb and cerebral lobes. Chemical Senses 30 SUPPL.:317-318. DOI: 10.1093/chemse/bjh242.

Nikonov AA, Caprio J. 2007. Responses of Olfactory Forebrain Units to Amino Acids in the Channel Catfish Res. Journal of Neurophysiology 97:2490-2498. DOI: 10.1152/jn.01198.2006.

Nikonov A a, Finger TE, Caprio J. 2005. Beyond the olfactory bulb: an odotopic map in the forebrain. Proceedings of the National Academy of Sciences of the United States of America 102:18688-18693. DOI: 10.1073/pnas.0505241102.

Olivares J. 2019. Analysis of Olfactory Responses in the Telencephalon of the rainbow trout Oncorhynchus mykiss. PhD thesis. Universidad de Valparaiso.

Osorio R, Schmachtenberg O. 2013. Calcium-activated chloride channels do not contribute to the odorant transduction current in the marine teleost Isacia conceptionis. Journal of Fish Biology 83:1468-1473.

Poulin R, Marcogliese DJ, McLaughlin JD. 1999. Skin-penetrating parasites and the release of alarm substances in juvenile rainbow trout. Journal of Fish Biology 55:47-53. DOI: 10.1006/jfbi.1999.0970.

Reisert J, Reingruber J. 2019. Ca2+-activated Cl- current ensures robust and reliable signal amplification in vertebrate olfactory receptor neurons. Proc Natl Acad Sci USA 116:10531058.

Reutter K, Kapoor BG. 2005. Fish Chemosenses. Science Publishers, Enfield, USA.

Rolen SH, Caprio J. 2007. Processing of bile salt odor information by single olfactory bulb neurons in the channel catfish. Journal of neurophysiology 97:4058-4068. DOI: 10.1152/jn.00247.2007.

Rolen SH, Sorensen PW, Mattson D, Caprio J. 2003. Polyamines as olfactory stimuli in the goldfish Carassius auratus. The Journal of experimental biology 206:1683-1696. DOI: 10.1242/jeb.00338.

Sato Y, Miyasaka N, Yoshihara Y. 2005. Mutually Exclusive Glomerular Innervation by Two Distinct Transgenic Zebrafish. Science And Technology 25:4889-4897. DOI: 10.1523/JNEUROSCI.0679-05.2005.

Sato K, Sorensen PW. 2018. The chemical sensitivity and electrical activity of individual olfactory sensory neurons to a range of sex pheromones and food odors in the goldfish. Chemical Senses 43:249-260. DOI: 10.1093/chemse/bjy016.

Sato K, Suzuki N. 2000. The contribution of a Ca2+-activated Cl- conductance to amino-acidinduced inward current responses of ciliated olfactory neurons of the rainbow trout. $J$ Exp Biol 203:253-262. 
611

612

613

614

615

616

617

618

619

620

621

622

623

624

625

626

627

628

629

630

631

632

633

634

635

636

637

638

639

640

641

642

643

644

645

646

647

648

649

650

651

652

653

654

655

656

Satou M. 1990. Synaptic organization, local neuronal circuitry, and functional segregation of the teleost olfactory bulb. Progress in Neurobiology 34:115-142. DOI: 10.1016/03010082(90)90004-Z.

Satou M, Ueda K. 1978. Synchronized rhythmic discharges of the secondary olfactory neurons in carp. Brain Research 158:313-329.

Schmachtenberg O. 2006. Histological and electrophysiological properties of crypt cells from the olfactory epithelium of the marine teleost Trachurus symmetricus. Journal of Comparative Neurology 495:113-121. DOI: 10.1002/cne.20847.

Schmachtenberg O, Bacigalupo J. 2004. Olfactory transduction in ciliated receptor neurons of the Cabinza grunt, Isacia conceptionis (teleostei: haemulidae). European Journal of Neuroscience 20:3378-3386.

Schoppa NE. 2006. Synchronization of olfactory bulb mitral cells by precisely timed inhibitory inputs. Neuron 49:271-83. DOI: 10.1016/j.neuron.2005.11.038.

Silva L, Antunes A. 2016. Vomeronasal Receptors in Vertebrates and the Evolution of Pheromone Detection. Annual Review of Animal Biosciences 5:353-370. DOI: 10.1146/annurev-animal-022516-022801.

Sorensen PW, Caprio J. 1998. Chemoreception. In: The Physiology of Fishes, edited by Evands D.H. 375-405.

Sorensen PW, Stacey NE. 2004. Brief review of fish pheromones and discussion of their possible uses in the control of non-indigenous teleost fishes. New Zealand Journal of Marine and Freshwater Research 38:399-417. DOI: 10.1080/00288330.2004.9517248.

Speedie N, Gerlai R. 2008. Alarm substance induced behavioral responses in zebrafish (Danio rerio). Behavioural Brain Research 188:168-177. DOI: 10.1016/j.bbr.2007.10.031.

Tessarolo JA, Tabesh MJ, Nesbitt M, Davidson WS. 2014. Genomic Organization and Evolution of the Trace Amine-Associated Receptor (TAAR) Repertoire in Atlantic Salmon ( Salmo salar ). G3-Genes|Genomes|Genetics 4:1135-1141. DOI: 10.1534/g3.114.010660.

Tierney KB. 2015. Olfaction in Aquatic Vertebrates. Handbook of Olfaction and Gustation: Third Edition:547-564. DOI: 10.1002/9781118971758.ch23.

Valdés J, Olivares J, Ponce D, Schmachtenberg O. 2015. Analysis of olfactory sensitivity in rainbow trout (Oncorhynchus mykiss) reveals their ability to detect lactic acid, pyruvic acid and four B vitamins. Fish Physiology and Biochemistry 41:879-885. DOI: 10.1007/s10695015-0054-9.

Valentinčič T, Lamb C., Caprio J. 1999. Expression of a Reflex Biting/Snapping Response to Amino Acids Prior to First Exogenous Feeding in Salmonid Alevins. Physiology \& Behavior 67:567-572. DOI: 10.1016/S0031-9384(99)00112-2.

Valentincic T, Miklavc P, Kralj S, Zgonik V. 2011. Olfactory discrimination of complex mixtures of amino acids by the black bullhead Ameiurus melas. Journal of Fish Biology 79:33-52. DOI: 10.1111/j.1095-8649.2011.02976.x.

Wakisaka N, Miyasaka N, Koide T, Masuda M, Hiraki-Kajiyama T, Yoshihara Y. 2017. An Adenosine Receptor for Olfaction in Fish. Current Biology 27:1437-1447.e4. DOI: 10.1016/j.cub.2017.04.014.

Wanner AA, Genoud C, Friedrich RW. 2016. 3-Dimensional Electron Microscopic Imaging of the Zebrafish Olfactory Bulb and Dense Reconstruction of Neurons. Scientific Data 3:1-15. DOI: $10.1038 /$ sdata.2016.100.

Wanner AA, Genoud C, Masudi T, Siksou L, Friedrich RW. 2016. Dense EM-based reconstruction of the interglomerular projectome in the zebrafish olfactory bulb. Nature 
657

658

659

660

661

662

663

664

665

666

667

668

669

670

671

672

673

674

675

676

677

678

679

680

681

682

683

684

685

686

Neuroscience 19:816-825. DOI: 10.1038/nn.4290.

Weltzien FA, Höglund E, Hamdani EH, Døving KB. 2003. Does the lateral bundle of the medial olfactory tract mediate reproductive behavior in male crucian carp? Chemical Senses 28:293-300. DOI: 10.1093/chemse/28.4.293.

Whitlock KE. 2006. The sense of scents: olfactory behaviors in the zebrafish. Zebrafish 3:203213. DOI: 10.1089/zeb.2006.3.203.

Wilson RI, Mainen ZF. 2006. Early Events in Olfactory Processing. Annual Review of Neuroscience 29:163-201. DOI: 10.1146/annurev.neuro.29.051605.112950.

Wisenden BD, Rugg ML, Korpi NL, Fuselier LC. 2009. Lab and field estimates of active time of chemical alarm cues of a cyprinid fish and an amphipod crustacean. Behaviour 146:14231442. DOI: $10.1163 / 156853909 X 440998$.

Wullimann MF, Rink E. 2002. The teleostean forebrain: a comparative and developmental view based on early proliferation, Pax6 activity and catecholaminergic organization. Brain research bulletin 57:363-70.

Wullimann MF, Rupp B, Reichert H. 1996. Neuroanatomy of the Zebrafish Brain. Basel Boston - Berlin: Birkhäuser Verlag. DOI: 10.1007/978-3-0348-8979-7.

Yaksi E, von Saint Paul F, Niessing J, Bundschuh ST, Friedrich RW. 2009. Transformation of odor representations in target areas of the olfactory bulb. Nature neuroscience 12:474-482. DOI: $10.1038 / \mathrm{nn} .2288$.

Yamamoto Y, Hino H, Ueda H. 2010. Olfactory imprinting of amino acids in lacustrine sockeye salmon. PLoS ONE 5:1-9. DOI: 10.1371/journal.pone.0008633.

Yamamoto Y, Shibata H, Ueda H. 2013. Olfactory Homing of Chum Salmon to Stable Compositions of Amino Acids in Natal Stream Water. Zoological Science 30:607-612. DOI: $10.2108 / \mathrm{zsj} .30 .607$.

Yoshihara Y. 2014. Zebrafish Olfactory System. In: Mori K ed. The Olfactory System: From Odor Molecules to Motivational Behaviors. Springer Japan, 71-96. DOI: 10.1007/978-4431-54376-3_5.

Zippel HP. 1998. Mitral cells and ruffed cells. Annals of the New York Academy of Sciences:533-534. 


\section{Figure 1}

Rainbow trout (Oncorhynchus mykiss) as model system for teleost olfactory research.

Fig. 1. Rainbow trout (Oncorhynchus mykiss) as model system for teleost olfactory research. (A) Isolated olfactory rosette of a juvenile specimen. Inset: Exposed olfactory organs of $O$. mykiss. (B) Toluidine blue-stained cryosection of the olfactory lamellae from O. mykiss. Inset: Ultrastructural detail of the dendritic endings of a microvillous (m) and a ciliated (c) ORN. (C) Horizontal cryosection through the olfactory bulbs, stained with toluidine blue. (D) Transverse section through the sensory neuroepithelium, immunohistochemically labeled for $\mathrm{Ga}_{0}$ (red) to mark microvillous ORNs, and for PCNA (green) to label basal cells. Modified from Bazáes et al., 2013. (E) Synchronous responses to a mixture of amino acids, recorded from the olfactory epithelium (EOG), olfactory bulb (OB), and telencephalic areas $V v$ and $D p$ in a live anesthetized specimen of $O$. mykiss. Note prominent field potential oscillations during the odor response. From Olivares 2019, PhD thesis, Universidad de Valparaiso. (F) Top: Schematic drawing of the rainbow trout brain. The telencephalic olfactory areas Dp and VV are indicated in their respective sections. Below, ORN types, olfactory bulb circuitry and tracts to the telencephalon. ORN: Olfactory Receptor Neuron; OB: Olfactory bulb; Tel: Telencephalon; OT: Optic tectum; Cb: Cerebellum; R: Ruffed cell; MC: Mitral Cell; Gr: Granule Cell; CF: Centrifugal fiber; Vv: Ventral nucleus of ventral telencephalon; Dp: Dorsal posterior area; EOG, electroolfactogram. Scale bars: A: 1 mm, B: $300 \mu \mathrm{m}$; C: $500 \mu \mathrm{m}, \mathrm{D}: 100 \mu \mathrm{m}$. 

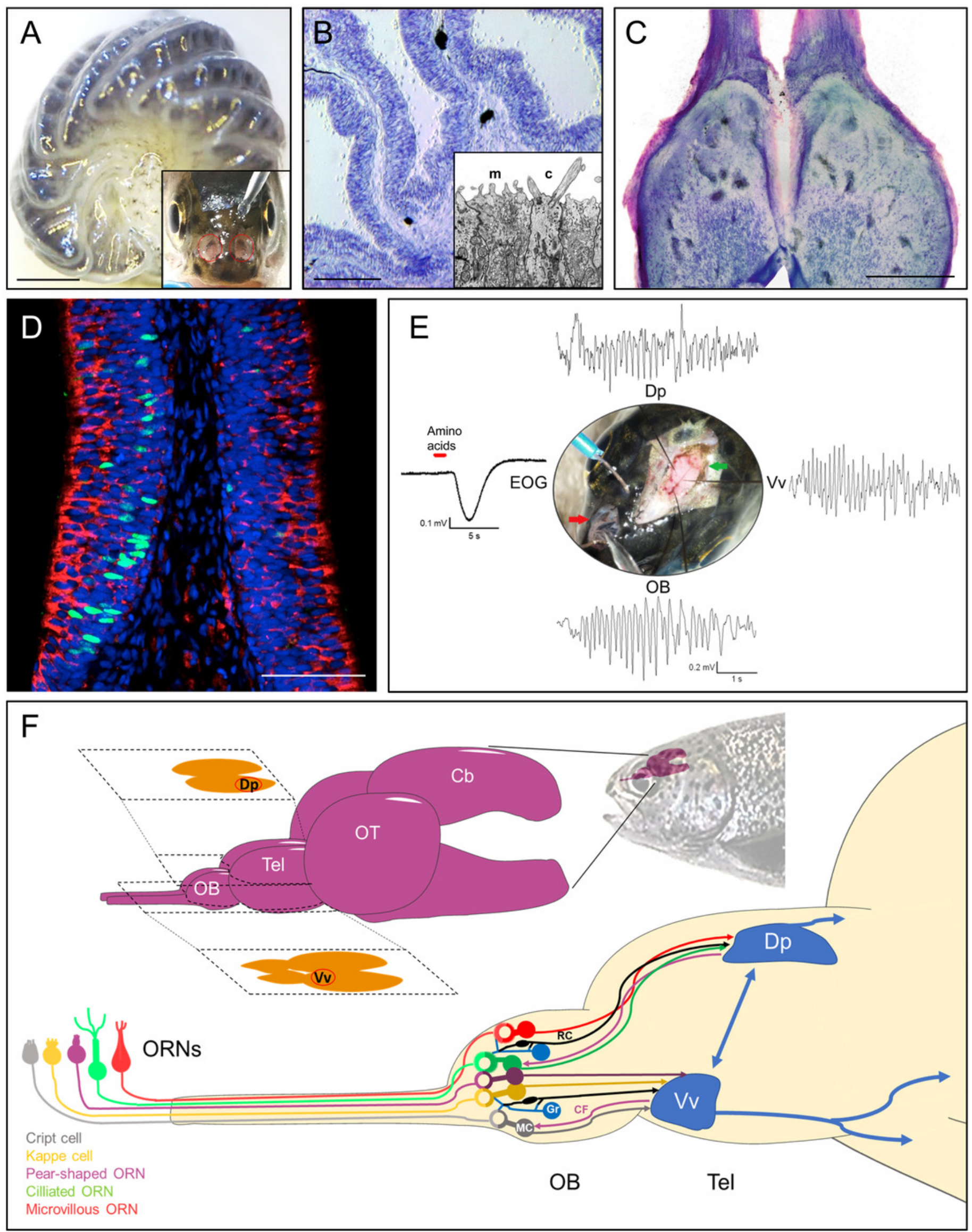